\title{
Strategy improves profits through the right investment for households in serikat tolong menolong setia sambu baru kecamatan medan barat
}

\author{
Khaira Amalia Fachrudin ${ }^{1 *}$, Elisabet Siahaan ${ }^{1}$, Paham Ginting ${ }^{1}$, Liasta Ginting ${ }^{1}$, Friska \\ Sipayung ${ }^{1}$ \\ ${ }^{1}$ Faculty of Economics and Business, Universitas Sumatera Utara, Medan, Indonesia \\ *Email: khaira@usu.ac.id
}

\begin{abstract}
Investment is very important to be done in order to obtain benefits in the future. Housewives also need to make this investment. This service aims to provide investment strategies and open householder insights to be able to choose the right type of investment and assist her husband in deciding to invest or support investments made by her husband. Lectures and assistance were given to 25 housewives in STM Sambu Baru, Medan Barat District. After reading the profiles of these mothers it is recommended that the right investment is pure gold. The result is that mothers who have not had investment become interested in investing in gold. Previously they did arisan money, now they change their arisan, i.e. the arisan money is bought pure gold and will be given to the arisan draw. They also agreed to invite their husbands to invest in land and thought to have land investment in their own name.
\end{abstract}

Keyword: Investment strategies, profits, housewives

\begin{abstract}
Abstrak
Investasi sangat penting dilakukan agar diperoleh manfaat di masa yang akan datang. Ibu rumah tangga juga perlu melakukan investasi ini. Pengabdian ini bertujuan untuk memberikan strategi investasi dan membuka wawasan ibu rumah tangga agar mampu memilih jenis investasi yang baik serta membantu suaminya dalam memutuskan berinvestasi atau mendukung investasi yang dilakukan suaminya. Ceramah dan pendampingan dilakukan kepada 25 ibu rumah tangga di STM Sambu Baru, Kecamatan Medan Barat. Setelah membaca profil ibu ibu ini maka disarankan bahwa investasi yang tepat adalah emas murni. Hasilnya adalah ibu ibu yang selama ini belum memiliki investasi menjadi tertarik untuk berinvetasi emas. Sebelumnya mereka melakukan arisan uang, sekarang mereka mengubah arisan mereka, yaitu uang arisan tersebut dibelikan emas murni dan akan diberikan pada yang menarik arisan. Mereka juga bersepakat untuk mengajak suami berinvestasi dalam bentuk tanah serta berfikiran untuk memiliki investasi tanah atas namanya sendiri.
\end{abstract}

Kata Kunci: Strategi investasi, keuntungan, ibu rumah tangga

\section{PENDAhUluan}

\subsection{Analisis Situasi}

Saat ini tingkat kebutuhan, gaya hidup dan budaya konsumerisme membuat sebagian rumah tangga tidak memiliki banyak uang yang diinvestasikan. Banyak pula ibu rumah tangga yang tidak mengenal instrumen investasi dan strateginya. Kebanyakan investasi dilakukan oleh suami dengan menabung di bank serta membeli tanah dan bangunan.

Pada situasi suami dan istri sama sama bekerja, ditemui beberapa kasus bahwa penghasilan istri digunakan untuk konsumsi rumah tangga dan penghasilan suami digunakan untuk investasi. Padahal istri pun perlu memiliki investasi yang keuntungannya bebas digunakannya untuk keluarga dan dirinya. Investasi dilakukan untuk meningkatkan kesejahteraan dan menjaga gaya hidup di masa tua. 
Investasi adalah komitmen untuk menanamkan sejumlah dana saat ini untuk memperoleh keuntungan di kemudian hari (Tandelilin). Investasi dapat dilakukan pada aset riil dan aset keuangan (Jones et al., 2009), seperti properti, emas, deposito, obligasi, reksadana, saham, sekuritas derivatif, peer-to-peer lending, dan sebagainya.

Ibu ibu akan dimotivasi untuk memiliki investasi karena investasi akan dapat menghasilkan keuntungan dengan risiko. Reiss (2017) mengatakan bahwa pada titik tertentu dalam kehidupannya, 90 persen wanita di Amerika akan melajang, bercerai, atau janda sehingga wanita harus bertanggung jawab atas keuangan mereka.

Investor wanita menghasilkan pengembalian yang lebih baik karena mereka biasanya membeli dan menahan investasi, sementara pria bertransaksi hingga 45 persen lebih sering. asi pria. Perempuan, di sisi lain, tetap berpegang pada tujuan jangka panjang sehingga lebih berhasil.

Investasi pada properti dapat dilakukan dalam bentuk tanah, rumah, ruko, ataupun apartemen. Investasi ini relatif aman dan risikonya rendah, namun memerlukan modal awal yang cukup besar. Keuntungan yang dapat diperoleh adalah dari sewa maupun kenaikan harga (Madian, 2018).

Hampir serupa dengan properti, investasi emas nilainya relatif stabil dan merangkak naik dari tahun ke tahun. Modal awal berinvestasi emas pun tidak terlalu besar. Investasi ini pun bersifat likuid alias mudah diuangkan kembali. Investasi emas mengikut tingkat inflasi (Tanuwidjaya, 2009). Saat uang kehilangan nilainya karena waktu, emas dapat mengikutinya. Kelemahan investasi emas ialah ia gampang dicuri.

Pada saat membutuhkan uang tunai, investor bisa langsung menjual emas yang dimiliki. Kelemahan dari investasi emas ada pada cara penyimpanannya. Bentuk emas yang ringkas, membuat emas mudah untuk dicuri. Deposito juga dapat dipilih untuk berinvestasi. Pada umumnya nilai keuntungan investasi tidak ada yang bisa menjaminnya, kecuali deposito. Depsito merupakan instrumen investasi yang aman karena dijamin oleh LPS (Lembaga Penjamin Simpanan).

Investasi lainnya adalah obligasi. Obligasi juga cukup aman terlebih yang dikeluarkan oleh pemerintah dalam bentuk ORI (Obligasi Ritel Indonesia). Tingkat pengembalian investasinya pun lebih tinggi daripada deposito.

Reksadana adalah investasi yang dapat meghasilkan keuntungan lebih tinggi daripada deposito dan obligasi tetapi likuid seperti emas. Ini termasuk instrumen investasi yang aman dan menguntungkan asalkan cara menempatkannya tepat.

Peer-to-peer lending atau investasi berbentuk pinjaman merupakan bentuk investasi aman dan menguntungkan yang tergolong baru di Indonesia, investasi ini memakai konsep sharing economy. Investasi saham dapat memberikan keuntungan yang lebih tinggi dan risiko yang lebih tinggi pula.

Investor dapat melakukannya melalui website perusahaan sekuritas dengan terlebih dahulu menjadi anggotanya. Pengetahuan tentang fundamental terkait ekonomi dan saham sangat diperlukan untuk menghindari kerugian. Demikian juga pengetahuan tentang analisis teknikal. Jika investor tidak memiliki ilmu yang cukup, ia bisa meminta bantuan seorang manajer investasi.

Pengabdian yang dilaksanakan ini berkaitan dengan peningkatan pemahaman ibu rumah tangga mengenai pentingnya investasi dan strateginya. Pemahamannya ini dapat disampaikannya juga kepada suami dan anak anaknya.

Serikat Tolong Menolong (STM) Setia Sambu Baru Kecamatan Medan Barat memiliki anggota sebanyak 40 orang. Alamat STM ini adalah di Jalan Danau Semayang Nomor 151 Kecamatan Medan Barat. Kegiatan mereka adalah melakukan tolong menolong dalam kehidupan bersosial dan melakukan arisan rutin. Ibu ibu ini adalah pengelola keuangan rumah tangga yang berperan dalam menciptakan kesejahteraan keluarga. Sebanyak $40 \%$ dari anggota ini bekerja sebagai pedagang, pengusaha salon, dan penjahit. STM Sambu Baru ini menjadi mitra pengabdian dosen wajib mengabdi yang bertopik strategi investasi bagi ibu rumah tangga agar mereka mampu mengelola investasinya secara lebih baik karena sebelumnya pemahaman mereka akan investasi masih minim. 


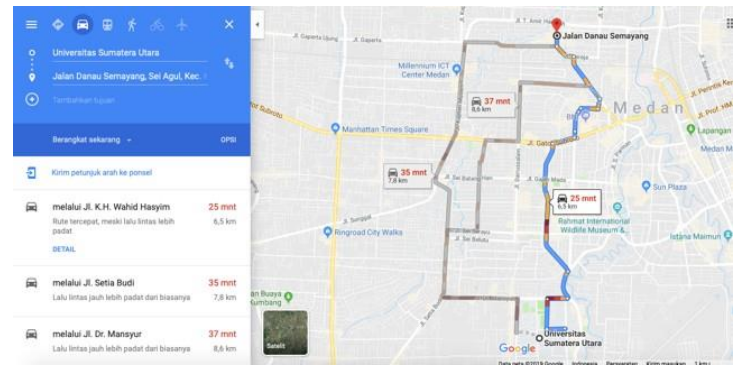

Gambar 1. Lokasi Pengabdian

Anggota STM ini sangat kompak. Mereka juga membentuk arisan yang mengutip iuran per bulan dan kemudian secara bergiliran menarik arisan tersebut dalam bentuk uang. Uang ini akan digunakan bagi yang menarik arisan untuk kebutuhan rumah tangganya. Bila ada anggota yang perlu dana mendesak seperti membayar uang sekolah anak, maka berdasarkan kesepakatan akan diberikan kesempatan untuk menarik terlebih dahulu. Dalam arisan ini mereka juga sering saling menjual barang barang seperti pakaian dan makanan.

Selain dari aspek keuangan, kelompok mitra sudah memiliki dasar dalam manajemen kelompok, dimana mereka membentuk diri sebagai sebuah perkumpulan arisan. Kesehariannya mereka berkumpul dan berbagi informasi untuk kepentingan bersama. Dasar ini sangat berpotensi untuk dikembangkan menjadi manajemen usaha kelompok (Purnaya, 2016). Solidaritas dan rasa saling mempercayai yang sudah dimiliki mitra akan sangat berpotensi dalam mendukung kesuksesan rencana kegiatan pengabdian yang dilakukan. Manajemen kelompok akan mendorong mitra menjadi lebih mandiri dan lebih kokoh dalam bersama mengelola kelompoknya. Kelompok ini dapat berkembang di tangan yang tepat.

\subsection{Permasalahan Mitra}

Dengan mengacu kepada analisis situasi ibu ibu rumah tangga STM Sambu Baru, maka permasalahan yang hendak diselesaikan pada pengabdian ini meliputi:

1. Mitra belum mampu menyisihkan penghasilan yang cukup untuk investasi dan sebahagian ibu ibu rumah tangga STM Sambu Baru belum semuanya memiliki investasi atas namanya sendiri

2. Mitra belum mengenal banyak instrumen investasi

3. Mitra belum mengetahui strategi berinvestasi

Pengusul bersama dengan mitra telah melakukan pembicaraan seputar prioritas dan manfaat dari pelaksanaan kegiatan pengabdian kepada masyarakat yang diajukan. Mitra akan mengetahui pentingnya menyisihkan penghasilan untuk investasi bagi keluarganya dan juga bagi dirinya. Mitra juga akan mengenal banyak istrumen investasi yang dapat dipilihnya sesuai toleransi risikonya.

\section{METODE PELAKSANAAN}

\subsection{Target}

Target pengabdian ini adalah :

1. Mitra akan mampu menyisihkan penghasilan yang cukup untuk investasi dan sebahagian ibu ibu rumah tangga STM Sambu Baru akan memiliki investasi atas namanya sendiri

2. Mitra akan mengenal banyak instrumen investasi dan memilih yang tepat bagi mereka sesuai profil risikonya.

3. Mitra akan mengetahui strategi berinvestasi.

Target luaran adalah berupa :

1. Artikel pada jurnal 
2. Video yang diunggah di youtube.

\subsection{Indikator Keberhasilan}

Keberhasilan pengabdian ini akan terlihat dari indikator sebagai berikut :

1. Mitra sudah mempunyai tekad yang kuat untuk berinvestasi

2. Mitra akan memotivasi suami dan anaknya

3. Sebahagian mitra sudah mulai berinvestasi dan atau meningkatkan investasinya, baik atas nama suami sebagai kepala keluarga maupun atas namanya sendiri.

4. Mitra sudah mampu memilih investasi yang tepat sesuai dengan profil risikonya

5. Mitra memahami strategi berinvestasi

Sedangkan indikator capaian luaran adalah apabila jurnal telah diterima dan video telah diunggah di youtube.

\subsection{Analisis perbandingan antara permasalahan mitra terhadap keseluruhan hasil yang dicapai}

Analisis perbandingan antara permasalahan mitra terhadap keseluruhan hasil yang dicapai disajikan dalam tabel 2.1

\begin{tabular}{|c|c|c|c|c|}
\hline NO & Permasalahan Mitra & Hasil Pengabdian & Feedback & $\begin{array}{l}\text { Harapan } \\
\text { Kedepan }\end{array}$ \\
\hline 1 & $\begin{array}{l}\text { Mitra belum mampu } \\
\text { menyisihkan penghasilan } \\
\text { yang cukup untuk } \\
\text { investasi dan sebahagian } \\
\text { ibu ibu rumah tangga } \\
\text { STM Sambu Baru belum } \\
\text { semuanya memiliki } \\
\text { investasi atas namanya } \\
\text { sendiri }\end{array}$ & $\begin{array}{l}\text { Mitra sudah } \\
\text { mempunyai tekat } \\
\text { yang kuat untuk } \\
\text { berinvestasi; } \\
\text { Memotivasi suami } \\
\text { dan anaknya; } \\
\text { Dan sebahagian } \\
\text { mitra sudah } \\
\text { meningkat kan } \\
\text { investasinya, bai k } \\
\text { atas nama suami } \\
\text { sebagai kepala } \\
\text { keluarga maupun } \\
\text { atas namanya } \\
\text { sendiri. }\end{array}$ & $\begin{array}{l}\text { Tim pengabdian } \\
\text { mendampingi dengan } \\
\text { terus memotivasi }\end{array}$ & $\begin{array}{l}\text { Mitra akan } \\
\text { secara mandiri } \\
\text { memilih } \\
\text { investasi yang } \\
\text { sesuai dengan } \\
\text { toleransi } \\
\text { resikonya }\end{array}$ \\
\hline 2 & $\begin{array}{l}\text { Mitra belum mengenal } \\
\text { banyak instrumen } \\
\text { investasi }\end{array}$ & $\begin{array}{l}\text { Mitra mengenal jenis } \\
\text { jenis instrument } \\
\text { investasi dan sudah } \\
\text { mampu memilih } \\
\text { investasi yang tepat } \\
\text { sesuai dengan profil } \\
\text { risikonya }\end{array}$ & $\begin{array}{l}\text { Tim pengabdian telah } \\
\text { berdiskusi secara } \\
\text { mendalam sehingga } \\
\text { pada tahap awal } \\
\text { mereka akan } \\
\text { berinvestasi emas } \\
\text { melalui arisan }\end{array}$ & $\begin{array}{l}\text { Arisan emas ini } \\
\text { akan tetap } \\
\text { dilanjutkan }\end{array}$ \\
\hline 3 & $\begin{array}{l}\text { Mitra belum mengetahui } \\
\text { strategi berinvestasi }\end{array}$ & $\begin{array}{l}\text { Mitra memahami } \\
\text { strategi berinvestasi, } \\
\text { yaitu membeli di } \\
\text { saat harga murah dan } \\
\text { akan menjual disaat } \\
\text { harga bagus }\end{array}$ & $\begin{array}{l}\text { Tim peneliti } \\
\text { mendampingi dan } \\
\text { terus memberi } \\
\text { motivasi agar jangan } \\
\text { sampai mitra menjual } \\
\text { investasinya dengan }\end{array}$ & $\begin{array}{l}\text { Mitra akan } \\
\text { mandiri }\end{array}$ \\
\hline
\end{tabular}


harga murah karena

kebutuhan mendesak

Tabel 2.1. analisis perbandingan antara permasalahan mitra terhadap keseluruhan hasil yang dicapai

\section{METODE PELAKSANAAN}

\subsection{Langkah Langkah dalam Penyelesaian Permasalahan Mitra}

Rencana kegiatan-kegiatan yang akan dilakukan dalam upaya penyelesaian permasalahan mitra dilakukan berdasarkan tahapan- tahapan pelaksanaan baik.

1. Tim pengabdian, mitra, beserta mahasiswa bersama- sama mempersiapkan lokasi yang akan dijadikan pusat aktivitas pengabdian.

2. Pemberian transfer ipteks terkait pengetahuan tentang investasi, instrumen investasi, dan strategi investasi.

3. Pendampingan mitra dalam memilih instrumen investasi dan strategi investasi.

4. Memberikan pemahaman sembari mempersiapkan mitra menjadi agent of change di lingkungan bermasyarakat

5. Evaluasi perubahan pada mitra dengan perbandingan awal sebelum diadakan kegiatan pengabdian sebagai evaluasi efektivitas kegiatan pengabdian.

\subsection{Metode Pendekatan}

Metode pendekatan yang dilakukan adalah berdiskusi dengan mitra, memberi pemahaman, dan pendampingan. Dilanjutkan dengan mempersiapkan ipteks dan transfer pengetahuan seputar investasi. Pendekatan pengabdian ini dilakukan dengan transfer ipteks melalui sosialisasi, pelatihan, serta pendampingan kepada mitra.

\subsection{Partisipasi Mitra}

Mitra berpartisipasi dan berperan aktif dalam memformulasikan wujud investasi mereka, sehingga diperoleh ide untuk melakukan arisan emas. Mitra juga mentransfer ilmu yang diberikan saat kegiatan ceramah dan pendampingan kepada anggota keluarganya. Mitra juga terus berkomunikasi dengan tim pengabdian mengenai masalah seputar investasi mereka.

\subsection{Evaluasi Pelaksanaan}

Kegiatan ini dievaluasi dua bulan setelah dilaksanakan pelatihan. Pengamatan dilakukan terhadap kegiatan arisan mereka. Potensi keuntungan investasi juga coba dihitung, walaupun hasilnya belum terlihat dalam jangka masa dua bulan, namun tim terus memberi semangat pada mitra untuk terus berinvestasi.

\section{HASIL DAN PEMBAHASAN}

\subsection{Hasil Kegiatan Pengabdian}


Lokasi ceramah dilakukan di rumah seorang anggota STM Setia Baru dan dihadiri oleh anggota lainnya, tim pengabdian, dan mahasiswa. Pemberian transfer ipteks terkait pengetahuan tentang investasi, instrumen investasi, dan strategi investasi dilakukan dengan alat bantu laptop dan infocus serta handout. Setelah itu dilakukan diskusi secara mendalam untuk memecahkan permasalahan mitra, terutama yang sulit menyisihkan uang untuk diinvestasikan dan ibu ibu yang belum punya investasi atas Namanya sendiri.

Mitra dalam meminta saran tentang investasi yang tepat pada kondisi saat ini, setelah mengidentifikasi profil risiko mereka maka disepakati bahwa mereka akan berinvestasi dalam bentuk emas dan tanah. Adapaun investasi pada saham dan surat berharga lainnya belum disarankan karena mitra yang umumnya berpendidikan sekolah menengah ini kurang memahami tentang return dan risiko saham.

Tim pengabdian terus memberikan pemahaman sembari mempersiapkan mitra menjadi agent of change di lingkungan bermasyarakat. Mitra mengatakan bahwa mereka juga mengajak teman teman lainnya untuk berinvestasi emas.

Evaluasi perubahan pada mitra sebelum diadakan kegiatan pengabdian dan sesudah dilakukan sebagai evaluasi efektivitas kegiatan pengabdian. Hasilnya terdapat perubahan yang baik, sebahagian dari mereka mulai memotong pendapatannya untuk diinvestasikan sebelum dikonsumsi, walaupun sedikit yang penting adalah memupuk kebiasaan baik.

\subsection{Luaran yang dihasilkan dan solusi yang ditawarkan}

Luaran yang dihasilkan adalah bahwa mitra telah membuat arisan emas. Selain itu, dalam anggota keluarga mereka juga mulai memikirkan investasi tanah. Strategi yang diajarkan tim pengabdian adalah bahwa mereka sebaiknya mencari tanah di daerah yang akan berkembang sehingga mereka akan mendapatkan return dari investasi ini. Walaupun penghasilan mereka tidak banyak, namun mereka bertekat untuk berinvestasi.

\section{KESIMPULAN}

\subsection{Kesimpulan}

Investasi sangat diperlukan walaupun pada masyarakat berpenghasilan rendah dan menengah. Kesadaran, pemilihan investasi dan strategi yang tepat perlu diajarkan dan dibudayakan. Mitra pengabdian ini sangat antusias dengan kegiatan pengabdian yang dilakukan dan mereka akhirnya mampu menyisihkan penghasilan yang cukup untuk investasi dan sebahagian ibu ibu rumah tangga STM Sambu Baru akan memiliki investasi atas namanya sendiri. Mereka juga mengenal banyak instrumen investasi dan memilih yang tepat bagi mereka sesuai profil risikonya serta telah mengetahui strategi berinvestasi.

\subsection{Saran}

Pemberian pemahaman dan pendampingan mengenai investasi pada ibu rumah tangga sangat penting dilakukan. Selanjutnya kegiatan ini dapat dilanjutkan pada kelompok ibu ibu lainnya.

\section{UCAPAN TERIMAKASIH}

Tim pengabdian mengucapkan terima kasih kepada Lembaga Pengabdian Kepada Masyarakat yang telah mendanai dengan dana NON PNBP Tahun Anggaran 2019. Nomor kontrak 780 / UN5.2.3.2.1/PPM/2019 Tanggal 23 Juli 2019. 


\section{DAFTAR PUSTAKA}

Giordano, Christine. 11 Great Investing Tips for Women. https://money.usnews.com/investing /slideshows/11-great- investing-tips-for-women

Jones, Charles P., Siddharta Utama, and Budi Frensidy. 2009. Investment Analysis and Management.

Madian, Andri. 2018. Kenali 6 Investasi Aman dan Menguntungkan bagi Pemula. Akselaran.com

Reiss, Dawn. 2017. Why Women Should Have Their Own Investments. Money.usnews.com

Tandelilin, Eduardus. 2010. Portofolio dan Investasi-Teori dan Aplikasi. Edisi Pertama. Penerbit Kanisius.

Tanuwidjaya, William. 2009. Cerdas Investasi Emas. MedPress. 